Arch Virol (1988) 99: 173-186



\title{
Identification of the structural proteins of turkey enteric coronavirus *
}

\author{
S. Dea and P. Tijssen \\ Centre de recherche en médecine comparée, Institut Armand-Frappier, \\ Université du Québec, Laval-des-Rapides, Québec, Canada
}

Accepted December 31, 1987

\begin{abstract}
Summary. Coronaviruses in the intestinal contents of turkey poults from Quebec flocks with outbreaks of enteritis were detected by electron microscopy. Five isolates were serially propagated in embryonic turkey eggs by inoculation of clarified intestinal contents into the amniotic cavity. Viral particles contained in the intestinal contents of infected embryos were purified by differential and isopycnic centrifugation in sucrose gradients. Intact virions present in fractions of densities 1.18 to $1.20 \mathrm{~g} / \mathrm{ml}$ were precipitated with trichloroacetic acid and the protein content was analyzed by sodium dodecyl sulfate-polyacrylamide gel electrophoresis. At least seven polypeptides with molecular weights ranging from 27,000 to 180,000 were regularly detected after electrophoresis of SDSsolubilized virions. Homologous rabbit antisera to turkey coronaviruses and pooled sera from convalescent turkeys immunochemically stained five polypeptides of apparent molecular weights of 95,000, 72-75,000, 66,000, 52,000 and 27,000. A further polypeptide with a molecular weight of 140,000 appeared in the absence of 2-mercaptoethanol and probably represents a dimer of the 66,000 polypeptide. One Quebec isolate differed from the Minnesota strain by two of its polypeptides, but no antigenic variations could be demonstrated amongst the various isolates either by immuno-electron microscopy, hemagglutination inhibition, or enzyme immuno assays on nitrocellulose.
\end{abstract}

\section{Introduction}

Transmissible enteritis of turkeys (bluecomb disease) is an acute, highly infectious disease affecting turkeys of all ages, but especially poults. The principal clinical signs are anorexia, watery droppings, marked dehydratation, weight loss and, in extreme cases, mortality [26]. The lesions are limited to the intestinal mucosa $[1,28]$.

In the early 1970 's, a virus, that possesses the typical morphology of members

* This study was partly supported by the Medical Research Council of Canada and the Quebec Federation of Poultry Producers. 
of the family Coronaviridae, was identified as the primary etiological agent [18, $24,25]$. No cross-reaction of this agent with other coronaviruses has been found by immuno-electron microscopy $[18,27]$, but different isolates of the turkey coronavirus (TCV) were shown to be antigenically identical or closely related [27]. Attempts to adapt and propagate the Minnesota strain of TCV to different cultures of primary chicken and turkey embryonic cells were unsuccessful, and for this reason the candidate turkey enteric coronaviruses have not been adequately characterized $[13,26]$. The prototype strain has been maintained by oral inoculation of one-day old poults or inoculation of embryonated turkey or chicken eggs $[13,24]$.

More recently, coronavirus-like particles were incriminated in outbreaks of diarrhea in turkey poults in Quebec, Canada [11]. This study was undertaken in order to characterize the structural proteins of a few of these TCV isolates that were serially propagated in turkey embryos.

\section{Material and methods}

\section{Specimens}

Pooled intestinal contents were obtained from diarrheic poults purchased in southern Quebec, from three farms where repeated outbreaks of enteritis occured in the last two years. A few specimens were also obtained from a breeding farm with recent problems of severe enteritis affecting more than 30 per cent of poults aged between 2 to 3 weeks. The specimens were homogenized in ten volumes of $0.05 \mathrm{M}$ Tris- $\mathrm{HCl}$ buffer, $\mathrm{pH} 8.0$, and clarified by centrifugation at $5,000 \times \mathrm{g}$ for 30 minutes at $4^{\circ} \mathrm{C}$. The supernatants were then passed through Millipore membrane filters of $450 \mathrm{~nm}$ pore size and frozen at $-70^{\circ} \mathrm{C}$ until used.

The prototype Minnesota strain of TCV (Bluecomb agent) which had been serially propagated in embryonated turkey eggs [13] was kindly provided by Dr. B. S. Pomeroy (College of Veterinary Medicine, Univ. of Minnesota, St. Paul, MN).

\section{Virus propagation and purification}

Clarified clinical specimens were inoculated into the amniotic cavity of 22-to-24-day-old embryonated turkey eggs obtained from a source known to be free from the usual specific pathogens of turkeys. After inoculation, the eggs were incubated at $37^{\circ} \mathrm{C}$ for 3 to 4 days. Embryo intestines were then harvested and homogenized in ten volumes of TBS buffer $(50 \mathrm{mM}$ Tris, $150 \mathrm{mM} \mathrm{NaCl}, \mathrm{pH} 7.5)$ using a Waring blender. The homogenates were clarified by centrifugation at $10,000 \mathrm{~g}$ for 20 minutes and supernatants were used for subsequent inoculations and for the preparation of purified virus stocks.

For purification procedures, aliquots $(80 \mathrm{ml})$ of virus preparations were ultracentrifuged at $100,000 \times \mathrm{g}$ (Beckman, T30 rotor, Palo Alto, CA) for 3 to 4 hours at $4^{\circ} \mathrm{C}$ through 10 $15 \mathrm{ml}$ cushion of a 30 per cent $(\mathrm{w} / \mathrm{v})$ sucrose solution. The pellets obtained were then resuspended in $5 \mathrm{ml}$ of TBS and layered on top of a discontinuous gradient consisting of $3 \mathrm{ml}$ each of $20,30,40,50$, and 60 per cent (w/v) sucrose solutions. After an overnight centrifugation at $100,000 \times \mathrm{g}$ (rotor SW 27 ) at $4{ }^{\circ} \mathrm{C}$, opalescent bands were collected, dialysed overnight against TBS and recentrifuged at the same speed for 16 hours on a continuous 20 to 55 per cent (w/v) sucrose gradient. Fractions were collected and their optical density at $280 \mathrm{~nm}$ and buoyant density were determined.

Samples from both clarified clinical specimens and fractions from sucrose gradients were negatively stained with $2 \%$ sodium phosphotungstate acid, $\mathrm{pH} 7.0$, and examined by 
EM, as described previously [9]. Hemagglutinating (HA) activity was also used to monitor the presence of viral particles in fractions of the sucrose gradients. The assay was done using U-type microplates and rabbit or rat erythrocytes as mentioned in a previous report [11].

\section{Antisera production}

Sucrose gradient fractions containing the highest concentration of purified TCV, as determined by EM, optical density and HA, were used as inoculum. On day one, TCVnegative rabbits received a mixture of $0.5 \mathrm{ml}$ of purified viral antigen $(400 \mu \mathrm{g}$ protein, as determined by the method of Bradford [5]) and $0.5 \mathrm{ml}$ of complete Freund's adjuvant (Difco, Detroit, MI) intradermally at multiple sites $(50 \mu \mathrm{l}$ per site). On day 10 , they were reinjected intraperitoneally with a mixture of $0.5 \mathrm{ml}$ of antigen and $0.5 \mathrm{ml}$ of incomplete Freund's adjuvant. The animals were bled weekly to determine the presence of specific hemagglutination inhibiting $(\mathrm{HI})$ antibody titers [11]. The antisera were then inactivated at $56^{\circ} \mathrm{C}$ for 30 minutes and stored at $-20^{\circ} \mathrm{C}$ until used.

In order to eliminate unwanted non-specific antibodies, $1 \mathrm{~g}$ of egg ovalbumin (Sigma) or $1 \mathrm{~g}$ of normal egg homogenates was added to each $10 \mathrm{ml}$ of antisera, mixed with a vortex, and incubated at $4^{\circ} \mathrm{C}$ overnight. The precipitate was eliminated by centrifugation at $5,000 \times \mathrm{g}$ for $30 \mathrm{~min}$. The treated antisera were shown to be free of reactivity with normal egg homogenates by CIE [9].

\section{Immunoelectron microscopy}

Virus fractions used for immunization and intestinal contents collected from healthy and sick poults were evaluated for the presence of TCV. Fifty $\mu 1$ from clarified samples were mixed with an equal volume of specific antiserum (diluted 1/10 in PBS) and incubated 1 hour at room temperature. A drop was then deposited on a carbon formvar-coated grid and processed as previously described [10]. Control grids were prepared using a pre-immunization serum sample.

\section{Dot immunobinding assay}

Viral antigen suspensions prepared as described above were diluted $1: 20$ in TBS and applied as spots onto a Biodyne transfer membrane $(1.2 \mu \mathrm{m}$ pore size, Pall Ultrafine Filtration Corp., Glen Cove, NY) using a Bio-Dot microfiltration apparatus (Bio-Rad Laboratories, Richmond, CA). The membrane was then satured in blocking buffer (TBS containing 2 per cent skimmed mild and 1 per cent polyvinyl pyrrolidone (PVP 40, Sigma), washed twice in TBS and probed with twofold $(1: 100$ to $1: 6,400)$ dilutions of antisera prepared in the blocking buffer. The membrane was subsequently washed 3 times in TBS and incubated with peroxidase-conjugated anti-rabbit IgG antibody (Boehringer Mannheim Biochemicals) as described by Hawkes et al. [15]. Peroxidase was detected with 4-chloro-naphthol (Sigma) and $\mathrm{H}_{2} \mathrm{O}_{2}$.

\section{Electrophoresis of viral proteins}

Purified virus preparations were precipitated by adding 10 per cent trichloroacetic acid (Sigma) and sedimented by centrifugation at $5,000 \times \mathbf{g}$ for 30 minutes. The virus pellets were then washed twice with cold acetone, solubilized by adding $100 \mu 1$ of sample buffer (62.5 mM Tris-HCl, pH 6.9, 1 per cent sodium dodecyl sulfate (SDS), 10 per cent glycerol and 0.001 per cent bromophenol blue) containing 0,2 , or 5 per cent 2-mercaptoethanol, and incubated for 2 minutes at $95^{\circ} \mathrm{C}$. SDS-polyacrylamide gel elctrophoresis (SDS-PAGE) was then carried-out using the discontinuous buffer system described by Laemmli [19]. Stacking and resolving gels consisted, respectively, of 3 per cent acrylamide $(0.08$ per cent bis-acrylamide) and 10 per cent acrylamide $(0.27$ per cent bis-acrylamide). Electrophoresis was carried-out at $125 \mathrm{~V}$ for 5 to 6 hours, or overnight at $50 \mathrm{~V}$. Polypeptide bands were revealed by staining the gels with Coomassie brillant blue G-250 [19]. 


\section{Western blotting}

Replicas were prepared by electrophoretic transfer of proteins separated by SDS-PAGE to nitrocellulose sheets $(0.45 \mu \mathrm{m}$ pore size, Schleicher and Schuell, Keene, NH) using a Trans-Blot cell (Bio-Rad Laboratories, Richmond, CA). Blotting was performed at $50 \mathrm{~V}$ for 3 hours in buffer consisting of $25 \mathrm{mM}$ Tris- $190 \mathrm{mM}$ glycine ( $\mathrm{pH} 8.3$ ) and 20 per cent $(\mathrm{v} / \mathrm{v})$ methanol. Nitrocellulose sheets were then immersed for 60 minutes at room temperature in a blocking buffer (TBS $+1 \%$ BSA) and then incubated overnight at $4{ }^{\circ} \mathrm{C}$ in a 200 fold dilution of rabbit hyperimmune sera prepared in the same buffer. The nitrocellulose sheets were subsequently washed 3 times for 10 minutes in TBS with $0.05 \%(\mathrm{v} / \mathrm{v})$ Tween 20 , and bound antibodies were detected by incubation with $37 \mathrm{KBq}$ of ${ }^{125} \mathrm{I}$-labeled-protein A (New England Nuclear, Specific activity $37-185 \mathrm{MBq} / \mathrm{mg}$ ) prepared in the blocking buffer for 2 hours at room temperature. The sheets were again washed, dried at room temperature and autoradiographed on Kodak X-OMAT film for $24-48$ hours at $-70^{\circ} \mathrm{C}$ with the aid of an intensifying screen.

\section{Results}

Coronavirus-like particles (Fig. 1A) were observed by EM in the intestinal contents of diarrheic poults. The virions appeared as enveloped particles that were moderately pleomorphic, but mostly spherical in shape, with a diameter ranging between 48 to $230 \mathrm{~nm}$. Most particles were centrally depressed and surrounded by a fringe of well-defined and regularly spaced petal-shaped projections, 12 to $17 \mathrm{~nm}$ in length. A second fringe of small granular projections situated at the base of the largest bulbous projections could also be demonstrated on few viral particles (Fig. $1 \mathrm{~B}$ and $\mathrm{C}$ ).

Five isolates were serially propagated in embryonic turkey eggs by inoculation of clarified intestinal contents into the amniotic cavity. After three days of incubation, the contents of the duodenum, jejunum and ceca of the embryos were watery and gaseous. The ceca were markedly distended and filled with watery, greenish contents. There were generally very few deaths. Sucrose density gradient centrifugation of the material collected from the intestine of infected embryos yielded two opalescent bands and three absorbance peaks (Fig. 2). The predominant peak was found at densities of $1.18-1.20 \mathrm{~g} / \mathrm{ml}$. Aliquots from these fractions were shown to contain numerous intact virions and maximal HA activity (titers ranging from $1: 512$ to $1: 2048$ with rat erythrocytes). The other fractions contained only damaged particles and showed little HA activity. The short granular projections were more distinctive in particles which lost the typical club-shaped corona (Fig. 3A). Generally, this purification procedure allowed us to prepare approximately 100 to $200 \mu \mathrm{g}$ of viral material starting from the intestinal contents of 10 turkey embryos. According to EM, the resulting purified viral preparation contained approximately $10^{7}$ viral particles per $\mu$ g of protein.

Rabbit hyperimmune serum produced against the Minnesota strain was shown to inhibit the HA activity of the homologous virus; the antiserum had an $\mathrm{HI}$ titer of 512-1024. HI titers of pre-immune serum were below the detectable level. When aliquots of diluted hyperimmune serum were reacted with the material used for immunization, aggregates were observed by IEM (Fig. 3B). 

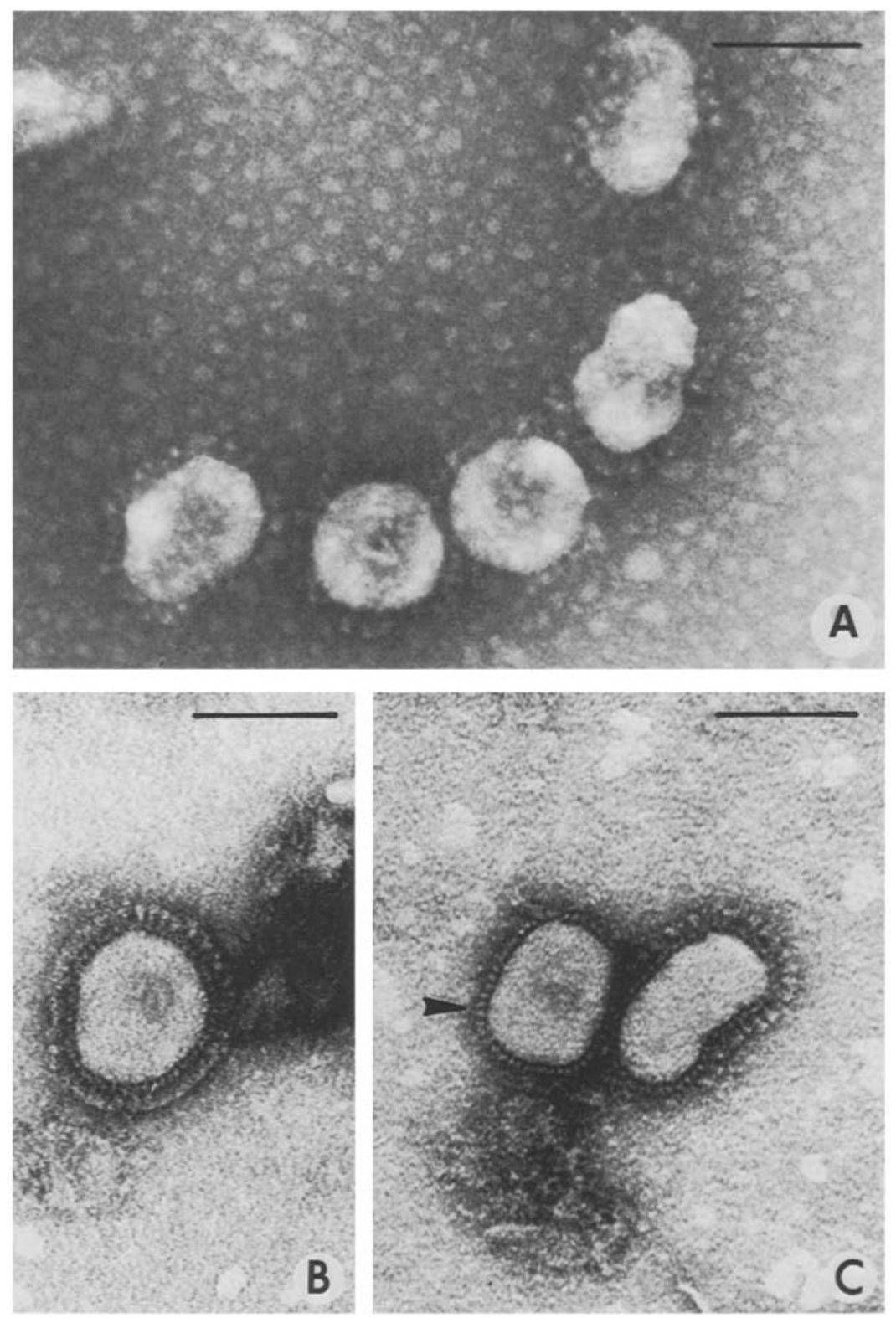

Fig. 1. A Transmission electron micrograph of coronavirus particles present in the intestinal contents of diarrheic poults. B A double fringe of surface projections was demonstrated on a few viral particles. C The short granular projections (arrow) were more distinctive on particles which lost the typical club-shaped corona. Bar $=100 \mathrm{~nm}$

Similar aggregates were observed by reacting the immune serum with clarified intestinal contents of embryos inoculated with the four Quebec isolates. No aggregates were obtained using intestinal contents of mock-infected embryos with antisera or using positive intestinal contents incubated with the pre-immune sera. Specific antibodies could also be revealed by the dot immunobinding assay. Titers from $1: 1,600$ to $1: 12,800$ were determined for each of the antisera when 


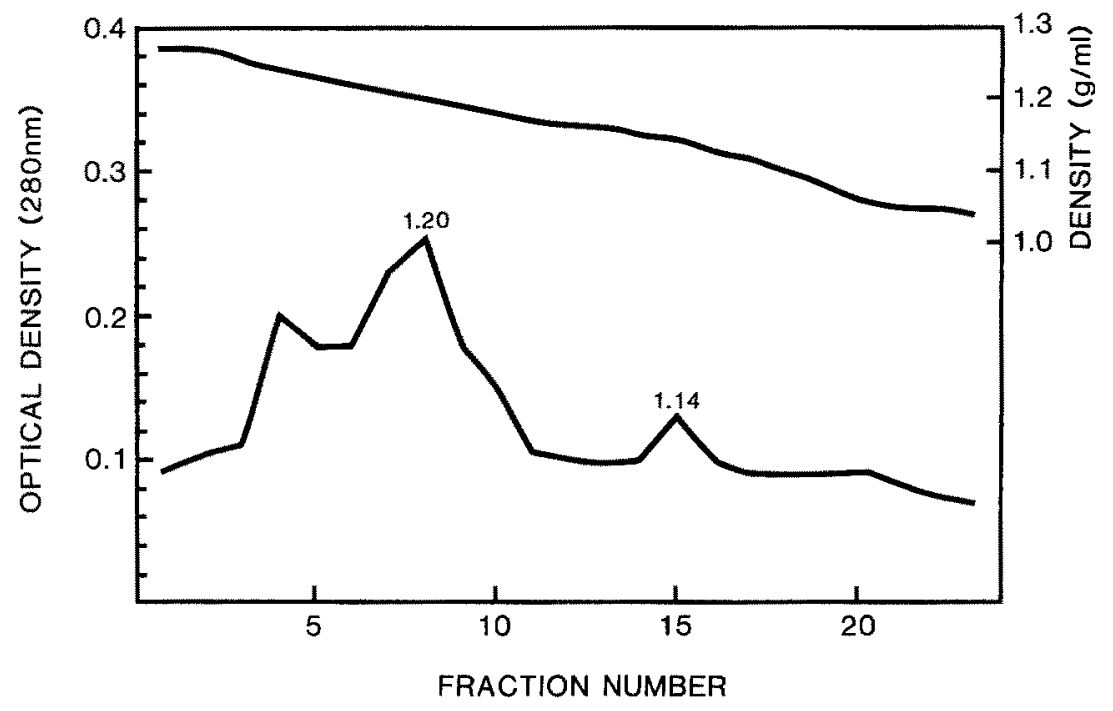

Fig. 2. Isopycnic purification of the egg-adapted Minnesota strain of turkey coronavirus in a sucrose gradient. Fractions were collected and their optical density at $280 \mathrm{~nm}$ was determined. The buoyant density values were obtained from the refractive index

tested against the homologous and/or heterologous TCV strains (Fig. 4). Obvious differences among these TCV isolates were not detected by these assays.

With the purified virus of the egg-adapted Minnesota strain, although numerous bands could be demonstrated by SDS-PAGE of the material present in sucrose gradient fractions corresponding to a buoyant density of $1.18-1.20 \mathrm{~g} /$ $\mathrm{ml}$, at least seven were reproducibly obtained. Further, only the latter polypeptides were still detectable after SDS-PAGE of the tenfold dilution of the original viral material (Fig. 5A). The approximate molecular weights of the virion polypeptides were determined by comparing their electrophoretic mobilities with those of commercial available standards (Bio-Rad Lab., Richmond, CA) in $8.0,10.0$ or $12.0 \%$ polyacrylamide slab gels (data not shown). In the absence of 2-mercaptoethanol (2-ME), five of these major polypeptides appeared as single bands corresponding to molecular weights of $140,000,95,000,72-$ 75,000, 34-38,000, and 24-26,000 (Fig. 5A). The addition of 2 per cent 2-ME in the disruption buffer caused the partial disappearance of the 140,000 band and an increase of the amount of a polypeptide migrating at 66,000 (Fig. 5B, track 6). A group of three to four closely migrating bands with mol. wt. between 48,000 and 56,000 were usually observed under these conditions, but a band corresponding to a mol. wt. of 52,000 was more predominant. Occasionaly, a polypeptide with a mol. wt. of 170,000 to 180,000 could be resolved with some preparations, but it generally remained stacked on top of the resolving gel. The patterns of polypeptide migration obtained with the four Quebec isolates were indistinguishable from that of the Minnesota strain (Fig. 5B).

After Western-blotting of the reduced proteins of the different TCV strains, five of the polypeptides shown in Fig. 5 were detectable with the homologous 

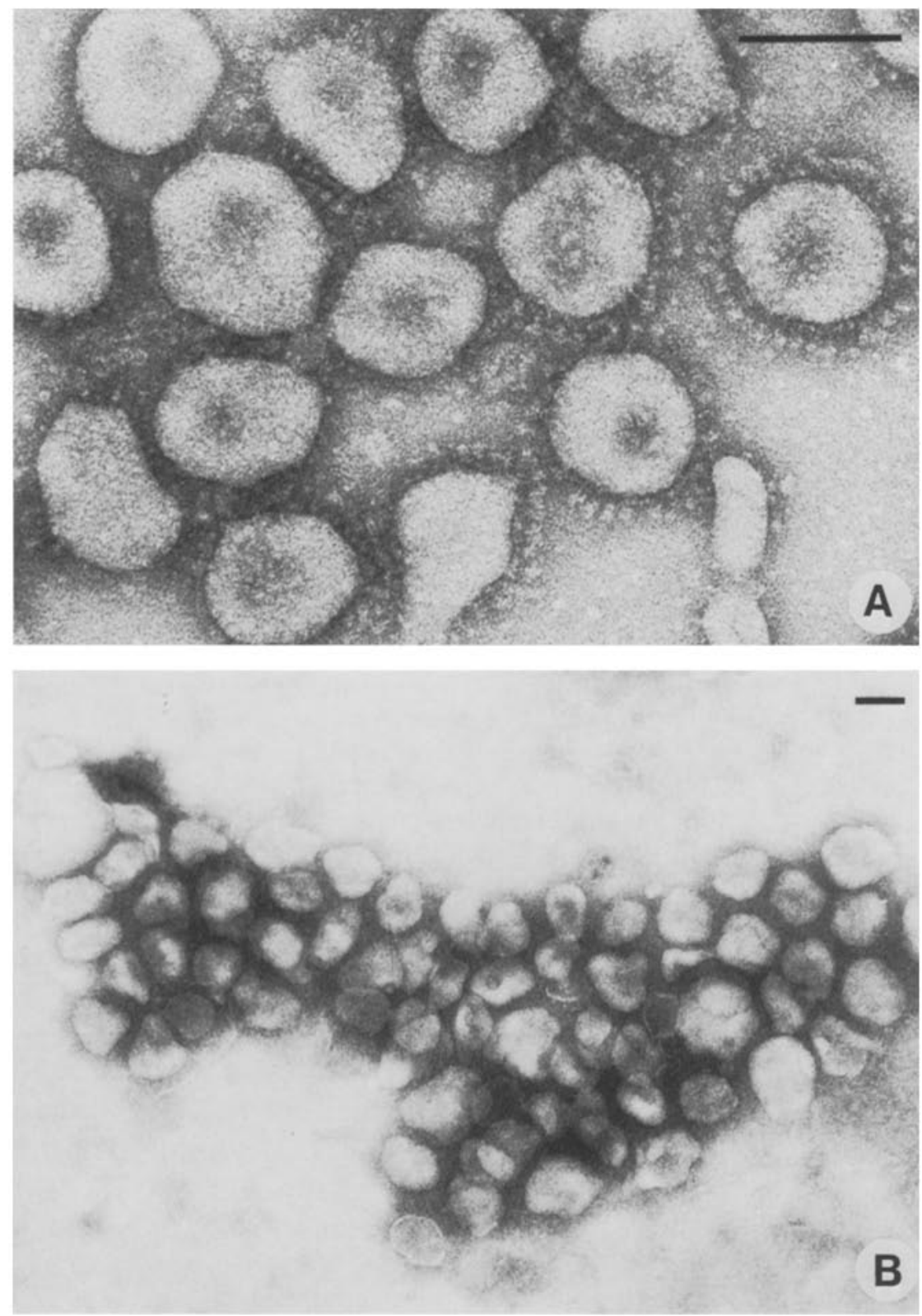

Fig. 3. A Electron micrograph of viral particles observed in sucrose gradient fractions of density 1.18 to $1.20 \mathrm{~g} / \mathrm{ml}$. B Immune aggregates observed by IEM following reaction of an aliquot of diluted rabbit hyperimmune serum with the viral fraction used for immunization.

$$
\mathrm{Bar}=100 \mathrm{~nm}
$$

antisera (Fig. 6A). In presence of 5 per cent 2-ME, the polypeptide with a mol. wt. of 140,000 could not be detected by the antisera, but a strong reaction was obtained with the polypeptide with mol. wt. of 66,000 . This suggested a possible dimer-monomer relation between these two polypeptides. However, following incubation with the heterologous antisera, differences could be detected among the various isolates at least for the structural polypeptides of molecular weights 


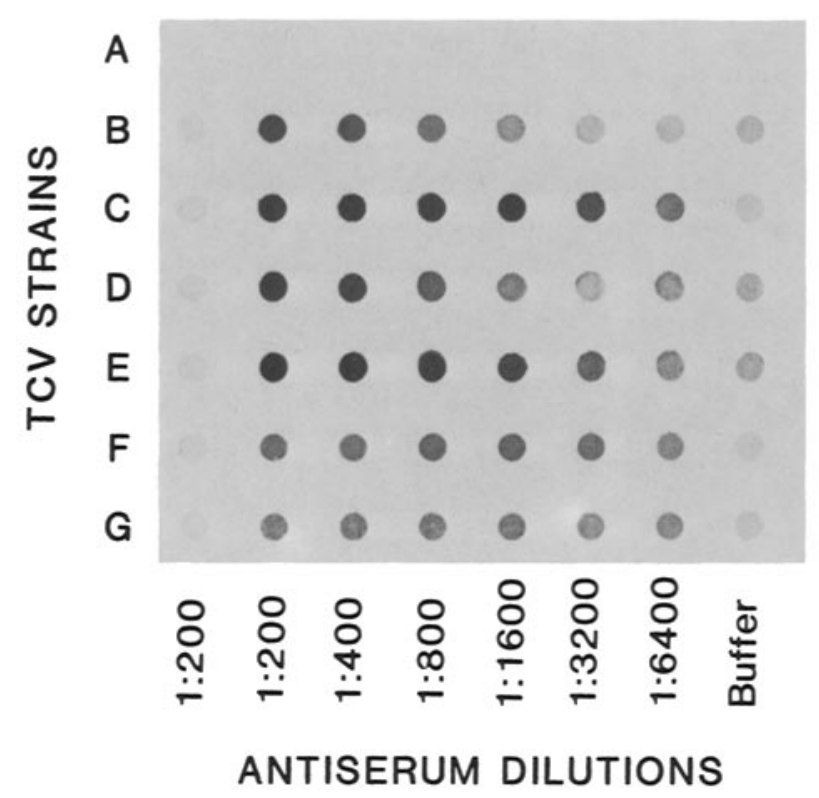

Fig. 4. Dot immunodotting analysis of rabbit hyperimmune sera produced against various isolates of TCV. Aliquot of viral antigen suspensions $(200 \mu \mathrm{l})$ were applied as spots onto a Biodyne transfer membrane and probed with two fold $(1: 100$ to $1: 6,400)$ dilutions of antisera prepared in the blocking buffer, as described in the text. $A$ Viral antigen + preimmunization serum; $B, C$ viral antigen prepared from Quebec isolate 84-2303 + immune sera produced against Quebec isolate 84-2303 (B) or Minnesota isolate $(C) ; D, E$ viral antigen prepared from Quebec isolate 84-2204 + immune serum prepared against the Minnesota isolate $(D)$ or Quebec isolate $84-2204(E) ; F, G$ viral antigen prepared from the Minnesota isolate + immune sera produced against Quebec isolates 84-2303 $(F)$ or 84$2204(G)$. No viral antigen was spotted on the first vertical lane serum control

74,000 and 66,000 . The antiserum produced against the Minnesota strain permitted the detection of only 3 of the structural polypeptides of the Quebec isolate $84-2303$. The 74,000 protein was only weakly revealed, while the 66,000 protein was not detected. Similar results were obtained using pooled sera from convalescent turkeys but the 52,000 protein was more intensively revealed than with the rabbit antisera (Fig. 6B).

\section{Discussion}

Coronaviruses were isolated from the intestinal contents of diarrheic turkey poults and serially propagated in embryonated turkey eggs inoculated via the amniotic route. Although there were generally very few deaths, microscopic changes observed at the level of the intestinal tract were sufficiently evident to confirm diagnosis of transmissible enteritis or bluecomb disease [13, 28]. The method used for virus purification and concentration from in vivo samples resulted in preparations containing sufficient amounts of well-preserved viral particles. The degree of virus purity was monitored by density determination, electron microscopic analysis and hemagglutination. The virions banded at a 


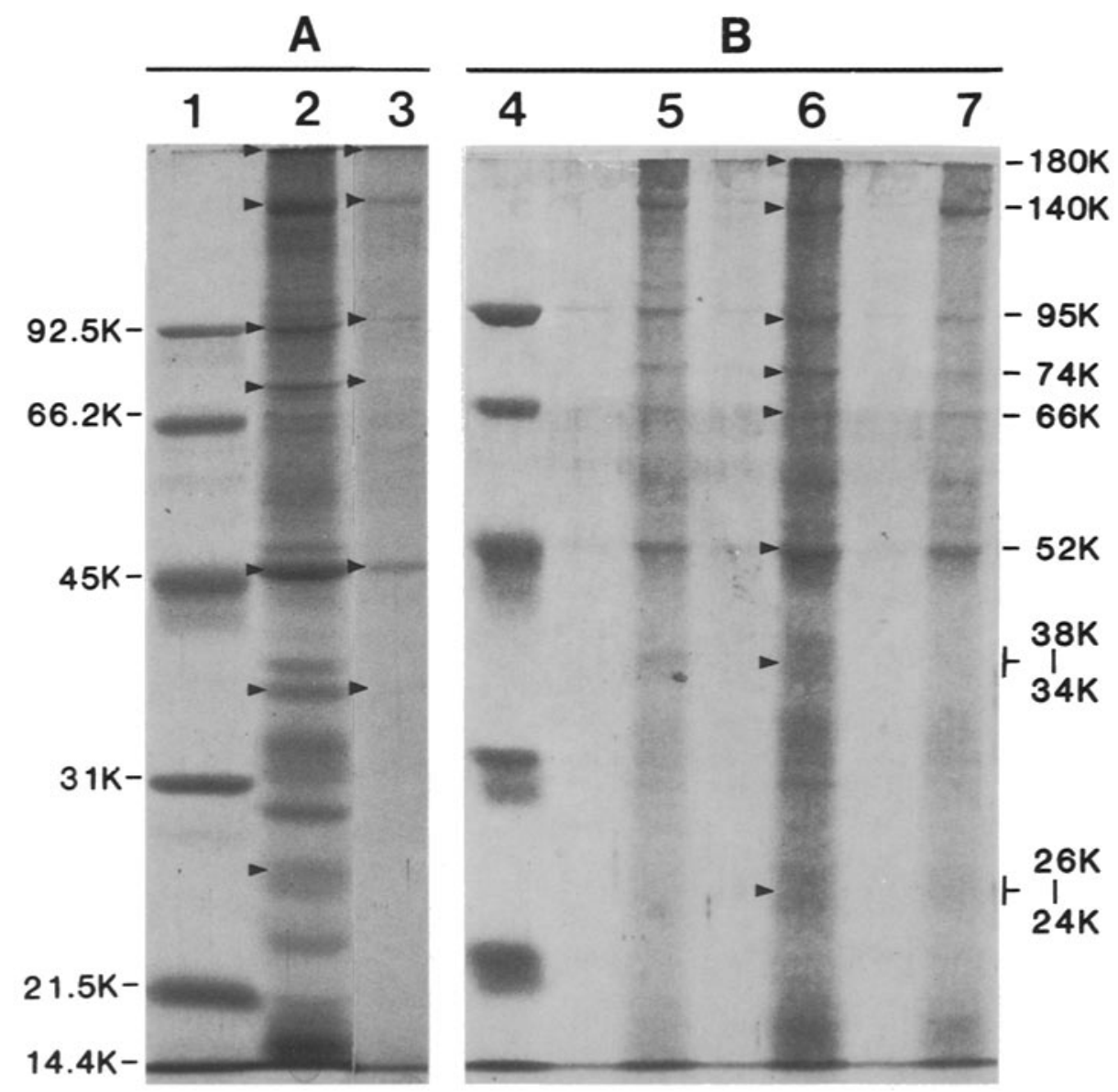

Fig. 5. SDS-PAGE analysis of TCV polypeptides. A PAGE profile of the Minnesota strain of TCV. Purified viral preparations were electrophoresed in 10 per cent gel under nonreducing conditions. 2,3 Each well was loaded with $100 \mu \mathrm{g}$ and $10 \mu \mathrm{g}$ of viral proteins, respectively, B Polypeptide profiles of various isolates of TCV. The specimens were electrophoresed in the presence of 2 per cent 2-mercaptoethanol. Similar profiles were obtained for the Quebec isolates 84-2303 (5) and 84-2204 (7), and the Minnesota strain (6) of TCV.

1, 4 Standard molecular weight proteins

buoyant density of $1.18-1.20 \mathrm{~g} / \mathrm{ml}$ in sucrose gradients, similar to reports for other animal coronaviruses [31].

Specific antisera were prepared in rabbits against the American prototype strain of TCV and three Quebec isolates. These isolates could not be differentiated either by IEM, HI, or enzyme immuno-assay on nitrocellulose. These results suggested the antigenic stability of the major antigenic determinants of the turkey enteric coronavirus isolates, in agreement with reports by Pomeroy et al. [27].

Reports on the structural proteins of coronaviruses agree on the presence of four to six structural proteins that can usually be grouped into three major size classes [31,34]. A predominant non-glycosylated protein with a molecular weight of approximately 50,000 represents the nucleoprotein, and a glycoprotein 


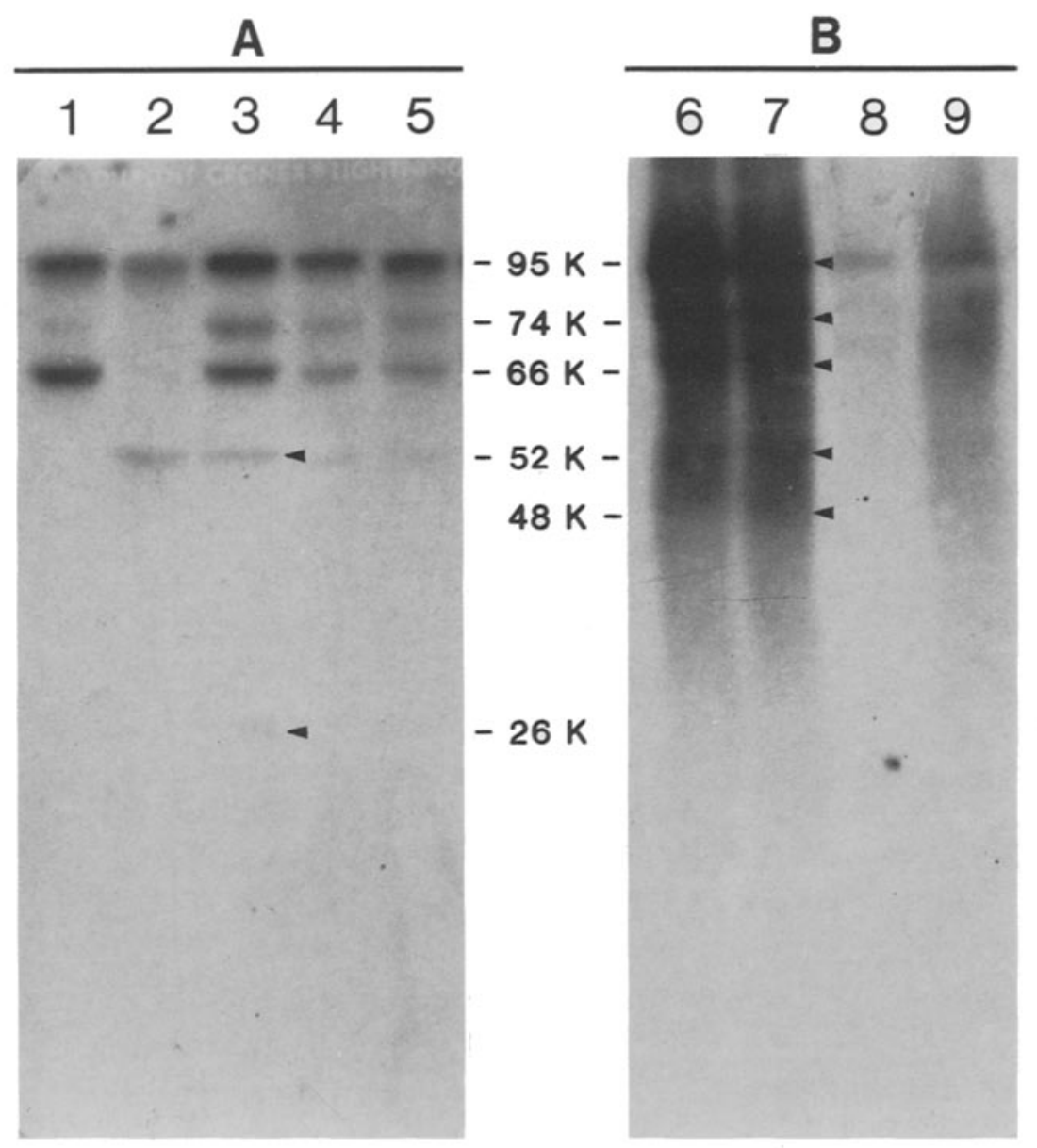

Fig. 6. Analysis of structural proteins of TCV isolates by Western immunoblotting. Purified viral preparations were electrophoresed in the presence of 5 per cent $2-\mathrm{ME}$. The proteins were transfered to nitrocellulose membrane and incubated with specific antiserum produced against the Minnesota strain $(\mathbf{A})$ or pooled sera from convalescence turkey $(\mathbf{B})$. Immunoblots were revealed by autoradiography after incubation with ${ }^{125}$ I-protein $A$, as described in the text. 1, 6 Quebec isolate 84 2303; 2, 8 Quebec isolate 85-2459; 3, 7 Minnesota strain; 4 Quebec isolate 84 403; 5, 9 Quebec isolate 84-2204

with an approximate mol. wt. of 30,000 associated with the envelope, is known as the matrix protein. The last class of coronavirion proteins is represented by glycoproteins of molecular weights ranging from 80,000 to 200,000 that form the characteristic surface projections [31,32]. However, all coronavirus species appear to contain a highly variable number of additional polypeptides as demonstrated in cases of MHV and IBV $[3,4,32]$. This makes it very difficult to compare the different coronavirus species with regard to their structural proteins. Many of these apparent variations in chemical composition may be due to different methods used for virus cultivation and purification, or different procedures used for protein-analysis.

In the present studies, we also reported the partial characterization of the 
structural polypeptides of the egg-adapted TCV strains. The preparation of "pure virus" and low quantity of material obtained at the end of the purification procedure, assignment of minor polypeptides, and contamination by host proteins raised difficulties in the analysis of the TCV polypeptide patterns. Similar problems were also mentioned for egg-adapted IBV strains [3, 21], and enteric coronaviruses of other species that were purified directly from fecal samples [2, $12,14]$. The polypeptide patterns shown by various TCV isolates when grown, purified and analysed under identical conditions were quite similar. At least 7 polypeptides with estimated mol. weights of $180,000,140,000,95,000,72-75,000$, $66,000,52,000$, and 24-26,000, were reproducibly detected after SDS-PAGE of the purified viral preparations. The immunoblotting analysis, using specific rabbit antisera that have been previously adsorbed against normal egg homogenates to eliminate unwanted antibodies, was considered for the final identification of the structural viral polypeptides. The polypeptide patterns obtained with the various $\mathrm{TCV}$ isolates correlated with the general polypeptide profiles of coronaviruses [31, 34].

Although the glycoproteins were not identified per se in this study, the aspect of the migration patterns obtained in 8,10 , and $12 \%$ polyacrylamide gels (variations in the electrophoretic mobility) suggested that at least the polypeptides with molecular weights of $180,000,140,000,90,000$, and 74,000 were glycosylated [29]. These polypeptides appear to be equivalent to the largest glycoproteins described for other coronaviruses, and may represent the peplomeric proteins in accordance with the findings of others investigators [31, 32, 33]. Nevertheless, the largest glycoproteins of TCV appear to differ fundamentally from those of the well-characterized MHV and IBV viruses. Whereas the largest peplomeric glycoproteins of these two viruses are not changed by the action of reducing agents such as 2-mercaptoethanol $[4,32,33,38]$, the 140,000 mol. wt.-protein of TCV appeared to be reduced to a presumptive 66,000 subunit. Interestingly, a similar $140,000 \mathrm{~mol}$. wt. glycoprotein, a disulfidelinked dimer, was described for three other hemagglutinating coronaviruses, namely the porcine hemagglutinating encephalomyelitis virus (HEV), the bovine enteric coronavirus (BCV) and the coronavirus DVIM of mice $[6,16,35]$. It has been suggested that this polypeptide may represent the hemagglutinin of these viruses which is probably located on granular projections situated at the base of the typical club-shaped corona of the virions $[17,35]$. Our observation by electron microscopy of two different types of surface projections on a few TCV particles also agree with the morphological features reported for the three above hemagglutinating coronaviruses and the model proposed by King and Brian [16]. The presence of a double fringe of surface projections has not been described for IBV, although the virus possesses an hemagglutinating activity $[34,38]$. The 180,000 and 95,000 molecular weight-proteins of TCV apparently correspond to other peplomeric glycoproteins described for coronaviruses, including IBV, TGE, HEV, and DVIM viruses [6, 22, 35, 38, 39]. By analogy with these other coronaviruses, the 52,000 and 26,000 molecular weight-poly- 
peptides probably represent the nucleoprotein and the glycosylated matrix protein, respectively [31]. A protein of 76,000 molecular weight has also been demonstrated for the rabbit enteric coronavirus [12], the HEV virus [6] and the IBV virus [7]. The exact nature of this protein is still unkown but it has been suspected to be a degradation product of the peplomers $[6,7]$.

Cross-reaction study by Western blotting revealed that possible antigenic variants of the Bluecomb coronavirus may exist. These variants may differ by few epitopes localized on the peplomeric proteins and possibly on the hemagglutin subunit of $66,000 \mathrm{~mol}$. weight. In general, primary and secondary structure epitopes are less affected by denaturation than tertiary or quaternary structure epitopes and thus, more likely to be recognized by antibodies in immunoblotting techniques [12]. Antibody binding to such conformation-dependent structures thus requires preservation of the native structure of the protein, which can be often achieved with the non-ionic detergent NP-40 [36]. Other reasons for the weak detection of the smallest polypeptide (mol.wt. 26,000) possibly include a relatively high degree of proteolysis in clinical specimens, or low immunogenicity (or low accessibility) of determinants. Production of monoclonal antibodies directed against defined epitopes of viral proteins and oligonucleotide finger printing of ribonucleic acids of different strains have been shown valuable tools to understand the antigenic diversity in cases of IBV and MHV viruses $[8,20,22,23,37]$. Such studies are presently in progress in order to establish the meaning of the differences observed amongst the Quebec TCV isolates.

\section{Acknowledgements}

The technical assistance of Mr. Jacques Beaubien is gratefully acknowledged.

\section{References}

1. Adams NR, Ball RA, Hostad MJ (1970) Intestinal lesions in transmissible enteritis of turkeys. Avian Dis 14: 392-399

2. Battaglia M, Passarani N, Di Matteo A, Gerna G (1987) Human enteric coronaviruses: Further characterization and immunoblotting of viral proteins. J Infect Dis 155: 140143

3. Bingham RW (1975) The polypeptide composition of avian infectious bronchitis virus. Arch Virol 49: 207-216

4. Bond CW, Leibowitz JL, Robb JA (1979) Pathogenic murine coronaviruses. II. Characterization of virus-specific proteins of murine coronaviruses JHMV and A59V. Virology $94: 371-384$

5. Bradford M (1976) A rapid and sensitive method for the quantitation of microgram quantities of protein utilizing the principle of protein-dye binding. Anal Biochem 72 : 248-254

6. Callebaut PE, Pensaert MB (1980) Characterization and isolation of structural polypeptides in haemagglutinating encephalomyelitis virus. J Gen Virol 48: 193-204

7. Cavanagh D, Davis PJ, Pappin DJC (1986) Coronavirus IBV glycopolypeptides: locational studies using proteases and saponin, a membrane permeabilizer. Virus Res 4: $145-156$ 
8. Clewley JP, Morser J, Avery RD, Lomniczi B (1981) Oligonucleotide fingerprinting of ribonucleic acids of infectious bronchitis virus strains. Infect Immun 32: 1227-1233

9. Dea S, Roy RS, Begin ME (1979) Counterimmunoelectroosmophoresis for detection of neonatal calf diarrhea coronavirus: methodology and comparison with electron microscopy. J Clin Microbiol 10: 240-244

10. Dea S, Roy RS, Elazhary MASY (1983) Virus-like particles, 45 to $65 \mathrm{~nm}$, in intestinal contents of neonatal calves. Can J Comp Med 47: 88-91

11. Dea S, Marsolais G, Beaubien J, Ruppanner R (1986) Coronaviruses associated with outbreaks of transmissible enteritis (Bluecomb) of turkeys in Quebec: hemagglutination properties and cell cultivation. Avian Dis $30: 319-326$

12. Descoteaux JP, Lussier G, Berthiaume L, Alain R, Seguin C, Trudel M (1985) An enteric coronavirus of the rabbit: detection by immuno-electron microscopy and identification of structural polypeptides. Arch Virol 84: 241-250

13. Deshmukh DR, Larsen CT, Pomeroy BS (1973) Survival of Bluecomb agent in embryonating turkey eggs and cell cultures. Am J Vet Res 34: 673-675

14. Hajer I, Storz J (1979) Structural polypeptides of the enteropathogenic bovine coronavirus strain LY-138. Arch Virol 59:47-57

15. Hawkes R, Niday E, Gordon J (1982) A dot-immuno-binding assay for monoclonal and other antibodies. Anal Biochem 119: 142-148

16. King B, Brian DA (1982) Bovine Coronavirus structural protein. J Virol 42: 700-707

17. King B, Potts BJ, Brian DA (1985) Bovine coronavirus hemagglutinin protein. Virus Res 2: $53-59$

18. King DJ (1975) Comments on the etiology and immunity of transmissible (coronaviral) enteritis of turkey (Bluecomb). Am J Vet Res 36: 555-556

19. Laemmli UK (1970) Cleavage of structural proteins during the assembly of the head of bacteriophage T4. Nature 227:680-685

20. Lai MMC, Stohlman SA (1981) Comparative analysis of RNA genomes of mouse hepatitis viruses. J Virol 38: 661-670

21. Lanser JA, Howard CR (1980) The polypeptides of infectious bronchitis virus (IBV41 strain). J Gen Virol 46: 349-361

22. Laude H, Chapsal JM, Gelfi J, Labiau S, Grosclaude J (1986) Antigenic structure of transmissible gastroenteritis virus. I. Properties of monoclonal antibodies direct against virion proteins. J Gen Virol 67: 119-130

23. Mockett APA, Cavanagh D, Brown TDK (1984) Monoclonal antibodies to the SI spike and membrane proteins of avian infectious bronchitis coronavirus strain Massachussetts M41. J Gen Virol 65: 2281-2286

24. Naqi SA, Panigraphy B, Hall CF (1975) Purification and concentration of viruses associated with transmissible (coronaviral) enteritis of turkeys (Bluecomb). Am J Vet Res 36: 548-552

25. Panigraphy B, Naqi SA, Hall CF (1973) Isolation and characterization of viruses associated with transmissible enteritis (Bluecomb) of turkeys. Avian Dis 17: 430-438

26. Pomeroy BS (1984) Coronaviral enteritis of turkeys. In: Holstad MS, Barnes HJ, Calnek BW, Reid WM, Yoder HW (eds) Disease of poultry, 8th edn. Iowa State University Press, Ames, pp 553-559

27. Pomeroy BS, Larsen GT, Deshmukh DR, Patel BL (1975) Immunity to transmissible (coronaviral) enteritis of turkeys (Bluecomb). Am J Vet Res 36: 553-555

28. Pomeroy KA, Patel BL, Larsen GT, Pomeroy BS (1978) Combined immunofluorescence and transmission electron microscopic studies of sequential intestinal samples from turkey embryos and poults infected with turkey enteritis virus. Am J Vet Res 39: 13481358

29. Segrest JP, Jackson RL (1972) Molecular weight determination of glycoproteins by polyacrylamide gel electrophoresis in sodium dodecyl sulfate. In: Ginsburg V (ed) Methods in enzymology, vol 28B. Academic Press, New York London, pp 54-56 
30. Siddell S, Wege H, Barthel A, Ter Meulen V (1981) Coronavirus JHM: intracellular protein synthesis. J Gen Virol 53: 145-155

31. Siddell S, Wege H, Ter Meulen V (1982) The structure and replication of coronaviruses. Curr Top Microbiol Immunol 99: 131-163

32. Sturman LS, Holmes KV (1977) Characterization of a coronavirus. II. Glycoproteins of the viral envelope: tryptic peptide analysis. Virology 77: 650-660

33. Sturman LS, Holmes KV, Benke J (1980) Isolation of coronavirus envelope glycoproteins and interaction with the viral nucleocapsid. J Virol 33: 449-462

34. Sturman LS, Holmes KV (1983) The molecular biology of coronaviruses. Adv Virus Res 28: 35-112

35. Sugiyama K, Ishikawa R, Fukuhara N (1986) Structural polypeptides of the murine coronavirus DVIM. Arch Virol 89: 245-254

36. Talbot PJ, Knobler RL, Buchmeier MJ (1984) Western and dot immunoblotting analysis of viral antigens and antibodies: application to murine hepatitis virus. $\mathbf{J}$ Immunol Methods 73: 177-188

37. Talbot PJ, Salmi AA, Knobler RL, Buchmeier MJ (1984) Topographical mapping of epitopes on the glycoproteins of murine hepatitis virus-4 (Strain JHM): correlation with biological activities. Virology 132: $250-260$

38. Waday CN, Westaway EG (1981) Structural proteins and glycoproteins of infectious bronchitis virus particles labelled during growth in chick embryo fibroblasts. Intervirology 15: 19-27

39. Wege H, Wege H, Nagashima K, Ter Meulen V (1979) Structural polypeptides of the murine coronavirus JHM. J Gen Virol 42: 37-47

Authors' address: Dr. P. Tijssen, Institut Armand-Frappier, Centre de recherche en médecine comparée, 531 boulevard des Prairies, Laval-des-Rapides, QC H7V 1B 7, Canada.

Received October 13, 1987 